\title{
Effect of Shoulder Abduction Angles on EMG Activity of the Abdominal Muscles during Single Leg Holding on the Foam Roller
}

\author{
Sung joon Yun', Jun hee Kim² \\ 'Department of Rehabilitation Medicine, Wonju Severance Christian Hospital, Yonsei University, Wonju, Korea; ${ }^{2}$ Department of Physical Therapy, \\ College of Health Science, Laboratory of Kinetic Ergocise Based on Movement Analysis, Yonsei University, Wonju, Republic of Korea
}

Purpose: This study examined the electromyography (EMG) activity of the abdominal muscles and the ratio of the oblique abdominal muscle activity to the rectus abdominis muscle during a single-leg holding position with isometric shoulder abduction (SLHISA) in the supine position on a foam roller.

Methods: Nineteen healthy males were recruited to the study. Each subject was asked to lay on a round foam roller and perform singleleg (nondominant) holding with contralateral shoulder abduction to one of three angles $\left(45^{\circ}, 90^{\circ}\right.$, or $\left.135^{\circ}\right)$ in random order. The surface EMG signals of the bilateral rectus abdominis (RA), external oblique abdominis (EO), and combined internal oblique abdominis (IO) and transverse abdominis (TrA) muscle were collected during the tasks. The EO/RA and (IO \& TrA)/RA ratios were determined using surface EMG. One way repeated measure ANOVA with three SLHISAs was used to assess the significant abdominal muscle EMG activity and the ratio of the oblique abdominal muscles activity to the RA muscle. The statistical significance level was $p<0.05$.

Results: The results were as follows. The SLHISA $135^{\circ}$ showed significantly higher EMG activity of both RAs, left EO, and right IO \&t TrA muscles $(p<0.05)$. The right EO and left 10 and TrA muscles/RA were significantly different among the SLHISA angles. The SLHISA $45^{\circ}$ showed a significantly greater ratio of right EO/RA and left IO \& TrA/RA $(p<0.05)$.

Conclusion: SLHISA on a foam roller is useful for lumbopelvic stabilization exercise by increasing the activity and recruiting a specific pattern of the oblique abdominal muscle.

Keywords: Foam roller, Lumbopelvic stabilization, Oblique abdominis, Shoulder abduction.

\section{서 론}

최근 연구에서 폼롤러는 몸통 균형과 안정성을 향상시키는 훈련도 구로 많이 사용되어지고 있다. 폼롤러는 둥근 원기둥 모양을 하고 있 기 때문에 이 위에서 운동이 이뤄질 경우 몸통에 균형 동요를 유발하 여 이에 대항하여 균형 유지를 위해 몸통 양측 근육들의 전략적 사 용이 요구되어진다.' 따라서 폼롤러를 이용한 운동은 코어의 안정성 과 몸통 균형 전략을 개선하는데 도움이 될 수 있다.

팔과 다리가 움직임 포함된 활동을 하는동안 발생하는 몸통의 회 전에 대한 허리골반의 안정성(lumbopelvic stabilization)을 유지하기 위해서는 배근육의 적절한 동원(recruitment)이 중요하다. ${ }^{2}$ 이는 차에 서 내리거나 물건을 잡는 것과 같은 대부분의 일상생활이 팔과 다리 의 움직임 결합된 상태로 몸통이 반복적으로 회전하면서 이뤄지기
때문이다. ${ }^{3}$ Sahrmann ${ }^{4}$ 은 요통이 발생되는 이유에 대해 $\mathrm{L}_{5}-\mathrm{S}_{1}$ 부분을 지탱하는 배근육이 골반과 척추 사이의 회전을 제어하지 못하기 때 문이라고 하였고, 배근육의 적절한 동원과 동원 순서가 몸통 회전을 제어하는데 중요하다고 하였다.

배근육의 동원 패턴은 운동하는 바닥면의 상태, 움직임이 발생하 는 팔과 다리의 방향, 움직임의 각도와 외부 저항 유무에 영향을 받는 다.15-9 여러 연구자들이 불안정한 바닥면에서 이뤼지는 허리골반 안 정화 운동이 편평한 지면에서 운동할 때보다 배근육 중 대근육 그룹 (global muscle group)이 더 많이 활성화된다고 하였다.5,710 게다가 불안 정한 바닥면 중 짐볼(Gym ball)을 이용한 허리골반 안정화 훈련은 대 근육 그룹 중 배곧은근의 활성을 높이는데 효과적이라 보고하였다. 또한, Kim 등 5 은 불안정한 바닥면에서 수행하는 운동이 모든 배근육 의 높은 근활성도를 유발한다고 보고하였고, 폼롤러를 이용한 허리
Received Jul 12, 2020 Revised Jul 13, 2020

Accepted Aug 14, 2020

Corresponding author Sung joon Yun

E-mail yunsj0919@yonsei.ac.kr
Copylight ( 2020 The Korean Society of Physical Therapy

This is an Open Access article distribute under the terms of the Creative Commons Attribution Non-commercial License (https:// creativecommons.org/license/by-nc/4.0.) which permits unrestricted non-commercial use, distribution, and reproduction in any medium, provided the original work is properly cited. 
골반 안정화 운동에서 배바깥빗근(external oblique abdominis)과 배 속빗근과 배가로근(internal oblique and transvers abdominis)과 배가로 근은 팔과다리의 움직임에 영향을 받는다고 보고하였다.1

허리골반 안정화 운동의 효과를 검증할 때 배근육 중 대근육 그룹 과 소근육(local muscle group) 그룹들의 시너지 관계가 간과되는 경우 가 있다. 둘 중 하나의 근육 그룹이 활성화 되더라도 팔과 다리의 움 직임에 대해 몸통의 균형을 유지하기 어렵고, 특히 불안정한 바닥면 에서 이뤄지는 팔과 다리의 움직임에 따라 배근육의 다양한 동원 패 턴이 유도된다.1.5-711 몸통의 안정화 운동에서 대근육과 소근육의 적 절한 균형도 중요하지만 지렛대 팔(lever arm)이 짧은 소근육의 동원 이 우선되어야 하고 대근육에 비교하여 높은 근활성비가 몸통 안정 화를 위한 중요한 요소라 할 수 있다. 따라서 허리골반 안정성에 적절 한 훈련은 배근육 중 대근육과 소근육들 사이의 부적절한 근육 동 원 패턴을 파악할 수 있어야 하고, 이를 토대로 훈련을 실시하여 만족 스러운 결과를 도출할 수 있어야 한다.17

하지만 폼롤러 위에서 시행된 허리골반의 안정화 운동에서 어깨 관절 벌림 각도에 대한 배근육의 근활성도를 이용한 동원 패턴을 확 인한 연구가 부족한 실정이다. 따라서, 본 연구의 목적은 폼롤러 위에 바로 누워 한 다리를 들어올린 자세에서 반대측 어깨관절 벌림 각도 변화에 따른 양측 배근육의 활성도 차이와 근활성도의 비율을 확인 하여 적절한 허리골반 안정화 운동을 찾는데 있다.

\section{연구 방법}

\section{1. 연구대상자}

본 연구는 성인 남성 19 명의 자발적인 참여에 의해 시행되었고, 대상 자들의 일반적인 특성은 평균연령 $23.1 \pm 2.5$ 세, 평균 신장 $175.3 \pm 3.7$ $\mathrm{cm}$, 평균 체중 $68.9 \pm 7.5 \mathrm{~kg}$ 이었다. 연구에 참여한 대상자들은 지난 6 개월 이내에 허리 통증의 경험이 없는 사람, 폼롤러(Thera-Band Pro Foam Rollers $6 \times 36$ inch, Sammons Preston Rolyan, Bolingbrook, IL, USA) 위에 바로 누워 비우세 다리(nondominant leg)를 든 상태로 교 각자세를 5 초 이상 유지할 수 있는 사람으로 선정하였다. 만약 양측 다리 길이의 불일치, 척추측만증이나 척추후만증, 신경계 손상, 척추 수술의 과거력이 있는 사람들은 대상자에서 제외하였다. 우세 다리 (dominant leg) 선정은 대상자들에게 축구 공을 차도록 하여 공을 차 기 위해 사용된 다리를 우세 다리로 선정하였다. 모든 대상자들은 오 른쪽 다리가 우세 다리였다.

\section{2. 실험기기 및 도구}

\section{1) 표면근전도}

본 연구에서는 폼롤러 위에서 왼쪽 다리를 바닥에 딛은 상태에서 오
른쪽 어깨관절의 등척성 벌림(single leg holding with isometric shoulder abduction in hook lying, SLHISA)을 시켰을 때 배근육의 근활성도 비 교를 위해 표면 근전도 기기인 NORAXON Telemyo 2400T (Telemyo 2400T, NORAXON Inc., USA)시스템을 사용하였다. 근전도 수집률 (sampling rate)은 1,000 Hz였고, 대역통과필터(bandpass filter) 20-450 $\mathrm{Hz}$ 로 하였고, 잡음을 제거하기 위해 대역차단필터(notch filter) $60 \mathrm{~Hz}$ 를 사용하였다. 수집된 근전도 신호는 제곱평균 제곱근법(root mean squar, RMS)으로 처리하여 분석하였다.

근전도 자료수집은 양측 배곧은근(rectus abdominis), 배속빗근과 배가로근, 배바깥빗근으로부터 들어오는 신호를 이용하였다. McGill 등른 위앞엉덩뼈가시(anterior superior iliac spine) 주변에서 수집된 근전도 신호는 배속빗근과 배가로근의 결합된 근활성도 값으로 볼 수 있다고 하였다. 따라서 근전도 전극의 부착 위치는 1) 배곧은근: 배 꼽의 외측 $2 \mathrm{~cm}$ 지점, ${ }^{13}$ ) 배속빗근과 배가로근: 위앞엉덩빼가시와 두 덩결합 사이의 중간 지점, ${ }^{1,512} 3$ ) 배바깥빗근: 배꼽 외측과 위 앞엉덩이 뼈가시 위를 만나는 지점을 선택하였다. ${ }^{14}$ 근전도 전극을 부착하기 위 해 전극 부위를 면도기로 털을 제거하고 의료용 알코올로 닦아내고, 표면 전극을 부착하였다. 수집된 신호는 MyoResearch 1.06 XP software package (Noraxon)을 이용하여 분석하였다.

\section{2) 근활성비(Muscle Activity Ratios)}

특정 운동 자세를 취할 때 배바깥빗근, 배속빗근과 배가로근들의 근 활성도를 배곧은근의 근활성도와 비교하여 비율이 높을수록 최적 의 허리골반 안정화 자세라고 할 수 있다.1,7 각각의 측정 자세를 유지 할 때 나타나는 양측의 배가쪽 빗근들과 배곧은근의 근활성비를 확 인하였다.

\section{3) 실험방법 및 자세}

대상자에게 폼롤러 위에서 오른쪽 다리 엉덩관절 $45^{\circ}$, 무릎관절 $70^{\circ}$ 굽힘된 상태로 바닥을 딛게 하고, 왼쪽 다리는 무릎을 편 상태로 발 목에 목표점을 이용하여 과도한 엉덩관절의 굽힘을 막았다. 폼롤러 위에서 바로 누운 자세를 유지할 때 양 다리가 벌어지는 것을 막기 위 해 고무줄을 이용하였다. 실험 전 폼롤러와 실험과정의 적응을 위해 25 분(5분 적응훈련-10분 휴식시간-10분 적응훈련) 동안 적응훈련을 하였다. 대상자는 적응훈련이 끝난 후 근피로를 막기 위해 15 분 동안 휴식시간을 가진 후 실험을 진행하였다(Figure 1).

실험은 모든 대상자는 SLHISA 자세에서 몸통의 회전력을 주기 위 해 오른손에 $2 \mathrm{~kg}$ 덤벨을 들고 수평면(horizontal plane)에서 무작위로 3 개의 각도 $\left(45^{\circ}, 90^{\circ}\right.$ 또는 $\left.135^{\circ}\right)$ 중 하나의 각도로 어깨관절 벌림을 하 게하고, 그 자세를 5 초간 등척성 수축을 유지하게 한 후 표면근전도 자료를 수집하였다. 측정 자세의 정량화를 위해 각도계(goniometer) 
를 이용하여 자세를 확인하였다. 측정은 무작위로 3 개의 어깨관절 벌 림 각도별 $\left(45^{\circ}, 90^{\circ}\right.$ 또는 $\left.135^{\circ}\right) 3$ 번씩 반복되었고, 측정 간 3 분 휴식을 적용하였다. 어깨관절 벌림 각도별 휴식 시간은 6 분씩 적용하여 대상 자들의 근피로를 최소화하였다.

표면근전도 신호를 이용하여 어깨관절 벌림 각도별 배근육의 근

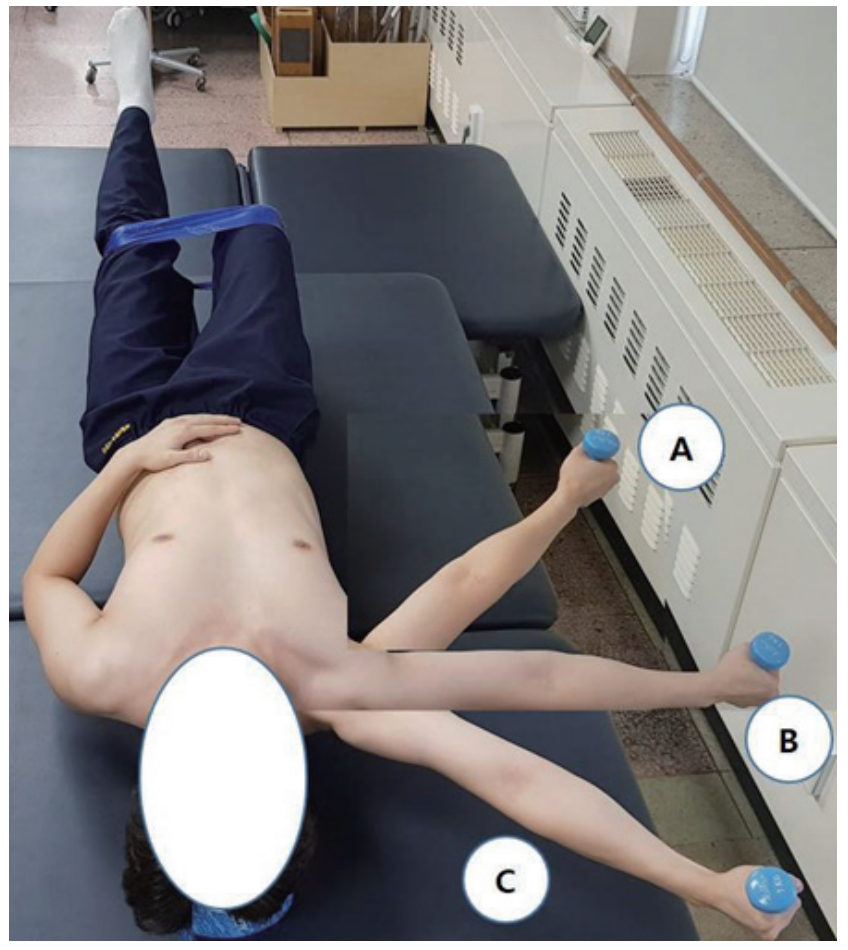

Figure 1. experimental posture.
활성을 비교하기 위해 최대 등척성 수축(Maximal voluntary isometric contraction, MVIC)을 사용하여 배근육의 근전도 신호를 표준화하였 다. \%MVIC는 각 근육별로 3 회씩 반복 측정하였다.,5

\section{3. 분석방법}

SLHISA 각도별 배근육의 근활성도와 배곧은근의 근활성도를 이용 한 양측 빗근들의 근활성비 차이를 검증하기 위해 반복측정 분산분 석(one-way repeated measure ANOVA)을 실시하였고, 사후검정은 Bonferroni 검정을 사용하였다. 모든 자료분석은 SPSS ver. 21.0 프로그 램(SPSS Inc., Chicago, IL, USA)을 이용하였고, 유의수준은 $\mathrm{p}<0.05$ 로 설정하였다.

\section{결 과}

\section{1. 어깨관절 벌림 각도에 따른 배근육의 근활성도 비교}

SLHISA 각도에 따라 양측 배곧은근과 배속빗근과 배가로근, 왼쪽 배 바깥빗근의 근활성도에서 통계학적으로 유의한 차이가 있었다 $(\mathrm{p}<0.05)$ (Table 1). SLHISA $135^{\circ}$ 에서 양측 배곧은근과 배속빗근과 배 가로근, 왼쪽 배바깥빗근의 근활성도가 유의하게 더 높게 나타났다 $(\mathrm{p}<0.05)$.

\section{2. 배곧은근에 대한 빗근의 근활성비}

양측 배곧은근의 근활성도를 이용하여 SLHISA 각도별 양측 배가쪽 빗근들의 근활성비를 비교했을 때 오른쪽 배바깥빗근과 왼쪽 배속

Table 1. EMG activity of each abdominal muscle expressed as a percentage of \%MVIC for 3 tasks

\begin{tabular}{|c|c|c|c|c|c|}
\hline Activity (\%) & $\mathrm{Abd} 45^{\circ}$ & $\mathrm{Abd} 90^{\circ}$ & Abd $135^{\circ}$ & $\mathrm{F}$ & $\mathrm{p}$ \\
\hline Right RA & $2.88 \pm 1.37^{f}$ & $3.85 \pm 1.80$ & $5.95 \pm 2.68$ & 17.52 & $<0.001^{+}$ \\
\hline Left RA & $4.70 \pm 1.95$ & $6.82 \pm 2.23$ & $10.62 \pm 4.84$ & 17.03 & $<0.001^{+}$ \\
\hline Right EO & $9.49 \pm 6.42$ & $10.95 \pm 9.01$ & $8.72 \pm 7.06$ & 3.09 & 0.072 \\
\hline Left EO & $8.24 \pm 4.59$ & $9.79 \pm 6.11$ & $11.65 \pm 9.13$ & 3.66 & $0.048^{*}$ \\
\hline Right IO \& TrA & $4.70 \pm 2.46$ & $6.05 \pm 4.23$ & $7.21 \pm 3.56$ & 8.72 & $0.002^{*}$ \\
\hline Left IO \&TrA & $14.40 \pm 9.75$ & $17.13 \pm 10.83$ & $16.53 \pm 8.43$ & 7.06 & $0.006^{*}$ \\
\hline
\end{tabular}

Values are expressed as mean \pm standard deviation. (SD) RA: rectus abdominis, EO: external oblique abdominis, IO: internal oblique abdominis, TrA: transversus abdominis, Abd: shoulder abduction.

${ }^{*} p<0.05,{ }^{+} p<0.001$.

Table 2. Comparisons of muscle activity ratios of oblique abdominis to rectus abdominis muscles activity

\begin{tabular}{|c|c|c|c|c|c|}
\hline Ratio (\%) & $\operatorname{Abd} 45^{\circ}$ & Abd $90^{\circ}$ & $\operatorname{Abd} 135^{\circ}$ & $\mathrm{F}$ & $p$ \\
\hline Right EO/RA & $3.30 \pm 2.23$ & $2.84 \pm 2.34$ & $1.47 \pm 1.19$ & 17.31 & $0.017^{*}$ \\
\hline Left EO/RA & $1.64 \pm 0.85$ & $1.57 \pm 1.10$ & $1.21 \pm 0.60$ & 0.99 & 0.283 \\
\hline Right IO \& TrA/RA & $1.75 \pm 0.98$ & $1.43 \pm 0.90$ & $1.10 \pm 0.86$ & 2.05 & 0.095 \\
\hline Left IO \&TrA/RA & $3.07 \pm 2.08$ & $2.51 \pm 1.59$ & $1.56 \pm 0.79$ & 11.06 & $0.016^{*}$ \\
\hline
\end{tabular}

Values are expressed as mean \pm standard deviation (SD).

EO: external oblique abdominis, IO: internal oblique abdominis, TrA: transversus abdominis, Abd: shoulder abduction.

${ }^{*} p<0.05$, The ratio of 1:1 indicates equal relative activity of the comparison muscle: rectus abdominis between ipsilateral side. 
빗근과 배가로근의 근활성비가 통계학적으로 유의한 차이를 보였다 $(\mathrm{p}<0.05)$ (Table 2). SLHISA 45에서 오른쪽 배바깥빗근과 왼쪽 배속빗 근과 배가로근이 양측 배곧은근과 비교한 근활성비가 유의하게 높 게 나타났다 $(\mathrm{p}<0.05)$.

\section{고 찰}

본 연구에서는 폼롤러 위에서 한쪽 다리를 든 상태에서 반대쪽 어깨 관절 벌림 각도의 변화가 배근육의 근활성도와 배곧은근과 배가쪽 빗근들의 근활성비에 미치는 영향을 확인하였다. SLHISA 각도에 대 한 배근육의 근활성도가 통계적으로 유의한 차이를 보였고 $(\mathrm{p}<0.05)$, SLHISA $135^{\circ}$ 에서 양측 배곧은근과 배속빗근과 배가로근, 왼쪽 배바 깥빗근의 근활성도가 유의하게 높았으며( $\mathrm{p}<0.05)$, SLHISA $45^{\circ}$ 에서 오른쪽 배바깥빗근과 왼쪽 배속빗근과 배가로근이 양측 배곧은근 과 비교한 근활성비가 유의하게 높았다 $(\mathrm{p}<0.05)$.

이전 연구에서 허리골반 안정화에 기여하는 배근육은 팔과 다리 의 움직임의 방향과 자세에 따라 근활성도의 변화를 보인다고 보고 하였다.1,15 특히 불안정한 바닥면에서의 시행한 팔다리 운동은 몸통 의 균형 동요를 유발하여 배곧은근과 배바깥빗근의 높은 근활성화 를 유발한다고 보고하였다.1,57 본 연구에서도 SLHISA에서 양측 배곧 은근의 높은 근활성도를 관찰할 수 있었다. 이전 연구들에서 불안정 한 바닥면에 등을 기대고 한쪽 다리를 드는 교각 운동을 하는 동안 배곧은근의 높은 근활성도를 보고하였는데, 이는 불안정한 바닥면 에서 다리를 들어올리는 동작이 엉덩관절의 굴곡 토크를 높이고 동 측(ipsilateral) 골반의 전방 기울임을 유발하여 몸통에 강한 회전 토크 를 발생시킬 수 있기 때문에 이를 상쇄하기 위해 대항근으로 배곧은 근이 활성화되어 허리골반 안정화를 돕기 때문에 불안정한 바닥면에 서 시행되는 운동이 안정한 바닥면보다 배곧은근의 활성이 더 크다 고보고되고 있다.1.5

Behm 등16은 외부 저항이 적용된 팔과 다리의 움직임이 포함된 허 리골반 안정화 운동이 자세조절과 관련한 몸통 근육의 활동을 촉진 시킨다고 보고하였고, 한쪽 팔에 저항을 적용하면 몸통의 균형에 동 요가 발생하게 되어 허리골반 안정화를 유지하기 위해 반대측 배근 육의 수축과 동원이 발생된다고 하였다. 본 연구의 결과 SLHISA 각도 에 대해 왼쪽 배바깥빗근은 통계적 유의한 차이를 보여, 이전 연구 결 과와 일치한다. 하지만 오른쪽 배바깥빗근은 유의한 차이를 보이지 않았다. 이는 $2 \mathrm{~kg}$ 덤벨을 든 상태로 어깨관절의 등척성 벌림 자세를 유지하기 위해서는 오른쪽 배바깥빗근과 어깨 주변 근육(큰가슴근 육, 작은 가슴근육과 앞톱니근)의 지속적인 수축이 유발되어, ${ }^{17}$ 어깨 관절의 벌림 각도에 대한 영향이 통계적으로 유의한 차이가 없었던 것으로 생각된다.
이전 연구에 따르면 배가쪽 빗근들은 척추의 안정성과 복압을 조 절할 수 있고, 등허리근막(thoracolumbar fascia)의 긴장도를 올릴 수 있어 허리골반 안정화에 중요한 역할을 한다고 보고하였다.1.7 이 근 육들은 폼롤러 위에서 누운 상태로 팔과 다리의 등척성 운동을 실시 할 때 허리골반 안정성을 유지하기 위해 다양한 패턴으로 동원되어 수축하게 된다. ${ }^{1.5}$ 본 연구에서는 SLHISA 각도가 배속빗근과 배가로 근의 근활성도에 영향을 주었다는 것을 확인하였고, SLHISA $135^{\circ}$ 에 서 다른 어깨벌림 각도에 비해 양측 배속빗근과 배가로근의 근활성 도가 통계적으로 유의하게 높음을 확인하였다. 이전 연구에서는 배 가로근은 팔의 움직임에 의해 발생하는 몸통의 회전에 대해 지속적 인 수축을 통하여 허리골반 안정화에 기여한다고 하였고, ${ }^{4}$ 추가 저항 을 제공하기 위해 사용하는 덤벨은 몸통의 회전 토크를 제공하며 배 근육의 비대칭 근활성도를 나타낼 수 있다고 하였다. ${ }^{717}$ 본 연구에서 는 폼롤러에서 왼쪽 다리를 든 상태에서 오른쪽 어깨관절 벌림을 동 시에 유지하는 자세를 취함으로써 엉덩관절 굴곡 토크가 배근육의 활성과 연관되어 왼쪽 배속빗근과 배가로근의 높은 근활성도가 나 타났고, 오른쪽 배속빗근과 배가로근은 오른쪽 어깨관절의 벌림 각 도에 따라 자세를 유지하는 근육들의 신장수축(eccentric contraction) 량의 변화와 지렛대 팔의 변화에 따라 어깨관절 주변 근육들의 근활 성도가 영향을 받기 때문에 어깨관절 벌림 각도의 변화에 대한 배속 빗근과 배가로근의 근활성도 차이는 선행 연구의 결과와 일치한다. ${ }^{17}$ 특히 SLHISA $135^{\circ}$ 에서 가장 큰 차이를 보이는 이유는 오른쪽 어깨관 절 주변 근육의 신장수축량이 가장 크게 작용으로 인한 것으로 사료 된다.

이전 연구의 결과에 의하면 배곧은근은 몸통의 기능적인 움직임 의 안정성에 기여도가 낮기 때문에 허리골반 안정화 운동을 수행할 때 배가쪽 빗근들에 비해 낮은 근활성도가 보여야 한다고 보고했다. 본 연구 결과 폼롤러에서 SLHISA 각도에 따라 배가쪽 빗근들과 배 곧은근의 근활성비가 유의한 차이를 보였고, 특히 SLHISA $45^{\circ}$ 에서 오른쪽 배바깥빗근과 왼쪽 배속빗근과 배가로근이 배곧은근과의 근활성비가 통계적으로 유의하게 높았다. 이전 연구에서도 폼롤러에 서 한쪽 다리를 드는 자세를 취했을 때 반대쪽 배바깥빗근과 배곧은 근과의 근활성비가 높다고 보고하였다. 이는 다리를 들어올림으로 인해 동측 배속빗근과 배가로근의 근활성도가 증가하고 몸통의 회 전에 의한 균형 동요를 상쇄시키기 위해 반대쪽 배바깥빗근이 대항 근으로 작용하여 높은 근활성도를 보이며, 이때 배곧은근과 근활성 비가 높게 나온다고 보고하였다. ${ }^{15}$ 몸통의 회전에 의해 발생하는 균 형 동요를 조절하기 위해 동원되는 배곧은근의 수축을 줄이기 위해 서는 배바깥빗근과 반대측 배속빗근과 배가로근의 동시 수축 조절 이 중요하고, 이런 동원 방법이 강화될 수 있는 허리골반 안정화 운동 이 중요하다고 보고하였다. 본 연구에서도 특정 어깨관절 벌림 각도 
가 배가쪽 빗근들과 배곧은근의 근활성비에 영향을 주고 선택적으 로 근활성비를 높이는 자세를 조절할 수 있음을 확인하였다.

본 연구의 제한점은 첫째, 연구 대상자들이 우세 다리가 오른쪽인 건강한 젊은 남성으로만 구성되었다. 둘째, 오른쪽 어깨관절의 수평 면 벌림을 하는 동안 어깨관절 주변의 큰가슴근육, 작은 가슴근육과 앞톱니근의 근전도 자료를 수집하지 못하여 오른쪽 배곧은근과 배 바깥빗근의 근활성 변화를 설명할 수 없었다. 셋째, 폼롤러에서 팔다 리가 움직이는 동안 호흡 조절에 대한 안내가 없어 몸통에 균형동요 가 발생했을 때 배근육 이외에도 호흡근육의 활동으로 인한 복압의 상승을 통제하지 못하여 자세에 따른 배근육의 근활성도에 영향을 줄 수 있었다. 따라서 추후 연구에서는 폼롤러에서 팔과 다리의 움직 임이 포함된 허리골반 안정화 운동이 몸통 균형 능력이나 스포츠 활 동의 수행력에 어떠한 영향을 미치는지 알아보는 연구가 필요하다.

따라서 폼롤러 위에서 한쪽 다리를 든 상태에서 반대쪽 어깨관절 벌림 자세를 유지하는데 어깨관절 벌림 각도가 배근육의 근활성도 와 배곧은근과 비교한 근활성비에 영향을 준다는 것을 확인하였다. 폼롤러에서 허리골반 안정화 운동을 시행할 때 배근육의 강화를 위 해서는 SLHISA $135^{\circ}$ 의 운동이 권장되고, 허리 통증 환자의 초기 운동 으로는 배가쪽 빗근들의 동원 패턴을 이용한 SLHISA $45^{\circ}$ 을 추천할 수 있다. 폼롤러에서 특정 어깨벌림 각도를 이용한 운동은 배근육의 선택적 강화와 허리골반 안정화 운동의 강도를 결정지을 수 있을 것 으로 사료된다.

\section{REFERENCES}

1. Yun SJ, Kim MH. Effects of shoulder abduction in opposite directions on emg activity in the abdominal muscles during single leg raising in the supine position on the foam roller in healthy subjects. J Kor Phys Ther. 2015;27(4):270-4.

2. Kisner C, Colby L. Therapeutic exercise: Foundations and techniques. Philadelphia: FA, Davis \& Co, 2007:392-480.

3. Van Dillen LR, Sahrmann SA, Norton BJ et al. Reliability of physical ex- amination items used for classification of patients with low back pain. Phys Ther. 1998;78(9):979-88.

4. Sahrmann S. Diagnosis and treatment of movement impairment syndromes. Oxford, Elsevier Health Sciences, 2001:69-73.

5. Kim SJ, Kwon OY, Yi CH et al. Comparison of abdominal muscle activity during a single-legged hold in the hook-lying position on the floor and on a round foam roll. 2011;46(4):403-8.

6. Bak JW, Cho MK, Chung YJ. The effects of performing a one-legged bridge with hip abduction and unstable surface on trunk and gluteal muscle activation in healthy adults. J Kor Phys Ther. 2016;28(3):205-11.

7. Marshall PW, Murphy BA. Core stability exercises on and off a swiss ball. Arch Phys Med Rehab. 2005;86(2):242-9.

8. Kang KW, Son SM, Ko YM. Changes in abdominal muscle thickness and balance ability on plank exercises with various surfaces. J Kor Phys Ther. 2016;28(5):264-8.

9. Lim JH. Effects of flexible pole training combined with lumbar stabilization on trunk muscles activation in healthy adults. J Kor Phys Ther. 2018;30(1):1-7.

10. Lehman GJ, Hoda W, Oliver S. Trunk muscle activity during bridging exercises on and off a swissball. Chiropr Osteopat. 2005;13(1):14.

11. Choi YI, Kim JS, Kim SY. Influence of slashpipe exercise on symmetrical contraction of trunk muscle in normal adults. J Kor Phys Ther. 2019;31(5):298-303.

12. McGill S, Juker D, Kropf P. Appropriately placed surface emg electrodes reflect deep muscle activity (psoas, quadratus lumborum, abdominal wall) in the lumbar spine. J Biomech. 1996;29(11):1503-7.

13. Cram JR. Introduction to surface electromyography. London, Jones \& Bartlett, 1998:50-5.

14. Escamilla RF, Lewis C, Bell D et al. Core muscle activation during swiss ball and traditional abdominal exercises. J Orthop Sports Phys. 2010;40(5):265-76

15. Aruin AS, Latash ML. Directional specificity of postural muscles in feedforward postural reactions during fast voluntary arm movements. Exp Brain Res. 1995;103(2):323-32.

16. Behm DG, Leonard AM, Young WB et al. Trunk muscle electromyographic activity with unstable and unilateral exercises. J Strength Cond Res. 2005;19(1):193-201.

17. Myers TW. Anatomy trains: Myofascial meridians for manual and movement therapists. Edinburgh, Churchill Livingstone, 2009:131-48. 